\title{
Control of a non-isothermal continuous stirred tank reactor by a feedback-feedforward structure using type-2 fuzzy logic controllers
}

\author{
Mosè Galluzzo*, Bartolomeo Cosenza \\ Dipartimento di Ingegneria Chimica, Gestionale, Informatica, Meccanica, Università di Palermo, Palermo, Italy
}

\section{A R T I C L E I N F O}

\section{Article history:}

Received 25 November 2008

Received in revised form 30 January 2011

Accepted 30 March 2011

Available online 6 April 2011

\section{Keywords:}

Type-2 fuzzy logic controller

Non-isothermal CSTR

Bifurcation

Non-linear systems

\begin{abstract}
A B S T R A C T
A control system that uses type-2 fuzzy logic controllers (FLC) is proposed for the control of a non-isothermal continuous stirred tank reactor (CSTR), where a first order irreversible reaction occurs and that is characterized by the presence of bifurcations. Bifurcations due to parameter variations can bring the reactor to instability or create new working conditions which although stable are unacceptable. An extensive analysis of the uncontrolled CSTR dynamics was carried out and used for the choice of the control configuration and the development of controllers. In addition to a feedback controller, the introduction of a feedforward control loop was required to maintain effective control in the presence of disturbances. Simulation results confirmed the effectiveness and the robustness of the type- 2 FLC which outperforms its type- 1 counterpart particularly when system uncertainties are present.
\end{abstract}

(c) 2011 Elsevier Inc. All rights reserved.

\section{Introduction}

Systems characterized by high nonlinearities are difficult to control by controllers developed using linearized models, like traditional PID controllers. Although these controllers may be tuned in order to be effective at certain conditions, they are not very robust and may also destabilize the whole system if some parameters change. This is particularly true for systems which present bifurcations. These non linear systems are in fact dependent upon one or more parameters and their operative conditions are stable only if the values of these parameters remain within a limited range [18]. This is the case for the nonisothermal continuous stirred tank reactor considered in this work. If the reactor parameters, that behave as bifurcation parameters, go out of this range, and this can happen also for very small changes, then the initial equilibrium point may become unstable, or the reactor may also reach new equilibrium points that although stable are unacceptable as operative conditions of the reactor. Nonlinear controllers, like fuzzy logic controllers, are used to control such systems because they are much more robust and can handle the system parameter changes.

Two types of fuzzy logic controllers have been so far considered: type-1 [46] and type-2 [23,33,45]. Past works $[7,11,19,31,42,44]$ have shown the superiority of type- 2 fuzzy logic controllers over their type- 1 counter-parts. This is because type-2 fuzzy logic controllers can also handle uncertainties [26,34] present in the system and in the input data to the controller [15]. Type-2 fuzzy logic controllers [16,17] have been already applied in the field of process control: liquid level process control [44], wheeled mobile robot control [32], autonomous mobile robot [10], micro-robot [1], anaesthesia control [7], DC motor control [6], Kundur Test System [40], biochemical reactor [13], nth order nonlinear system [27], cable-driven parallel mechanism [4], inverted pendulum system [28], chaotic systems [29], multivariable nonlinear systems [30].

* Corresponding author. Address: Dipartimento di Ingegneria Chimica, Gestionale, Informatica, Meccanica, Università di Palermo, Viale delle Scienze ed. 6, 90128 Palermo, Italy. Tel.: +39 0916567272; fax: +39 0916571655.

E-mail address: galluzzo@unipa.it (M. Galluzzo). 
This paper presents the application of type-2 fuzzy controllers, with a mixed feedback-feedforward structure, to the control of an isothermal continuous stirred tank reactor (CSTR) that presents bifurcations. The simple feedback control is not adequate for the control of the reactor due to of the presence of several bifurcation parameters. Furthermore the uncertainty of parameters does not permit to have a robust controller.

A mixed feedback-feedforward control structure that makes use also of type-2 fuzzy controllers is proposed. It is a new approach that uses the feedforward control to cope with the presence of bifurcations that may arise from measurable disturbances and type- 2 fuzzy sets to make the control system more robust in particular if there is parameter uncertainty.

The approach is based on the knowledge of the continuation diagrams of the process model for choosing the control strategy. The model is obviously different from the real process but if the parameter uncertainties can be taken into account by the control system an optimal use of the knowledge of the process is achieved.

The paper is organised as follows: in Section 2, the mathematical model of the CSTR is introduced; in Section 3, the dynamic behaviour of the uncontrolled reactor is analysed; Section 4 discusses the two different types of controllers used in the simulation and their implementation; simulation results and discussion are given in Section 5; conclusions are presented in Section 6.

\section{CSTR model}

The case of a simple non-isothermal CSTR [25,41] is considered in this paper. The reactor is the one presented in various works by Perez and Albertos [38,39] in which the exothermic reaction A $\rightarrow$ B is assumed to take place. The heat of reaction is removed via the cooling jacket that surrounds the reactor. The jacket cooling water is assumed to be perfectly mixed and the mass of the metal walls is considered negligible, so that the thermal inertia of the metal is not considered. The reactor is also assumed to be perfectly mixed and heat losses are regarded as negligible. The reactor model equations, assuming constant volume and no control, are the following:

$$
\begin{aligned}
& \frac{\mathrm{dCa}}{\mathrm{dt}}=\frac{\mathrm{F}}{\mathrm{V}}\left(\mathrm{C}_{\mathrm{ao}}-\mathrm{C}_{\mathrm{a}}\right)-\alpha \cdot \mathrm{C}_{\mathrm{a}} \cdot \mathrm{e}^{(-\mathrm{E} / \mathrm{RT})} \\
& \frac{\mathrm{dT}}{\mathrm{dt}}=\frac{\mathrm{F}}{\mathrm{V}}\left(\mathrm{T}_{0}-\mathrm{T}\right)-\frac{\mathrm{H}}{\rho \mathrm{C}_{\mathrm{p}}} \alpha \cdot \mathrm{C}_{\mathrm{a}} \cdot \mathrm{e}^{(-\mathrm{E} / \mathrm{RT})}-\frac{\mathrm{UA}}{\rho \mathrm{VC}_{\mathrm{p}}}\left(\mathrm{T}-\mathrm{T}_{\mathrm{j}}\right) \\
& \frac{\mathrm{dT}_{\mathrm{j}}}{\mathrm{dt}}=\frac{\mathrm{F}_{\mathrm{j}}}{\mathrm{V}_{r m j}}\left(\mathrm{~T}_{\mathrm{j} 0}-\mathrm{T}_{\mathrm{j}}\right)+\frac{\mathrm{UA}}{\rho_{\mathrm{j}} \mathrm{V}_{\mathrm{j}} \mathrm{C}_{\mathrm{pj}}}\left(\mathrm{T}-\mathrm{T}_{\mathrm{j}}\right)
\end{aligned}
$$

The equations are obtained by a component mass balance (1), an energy balance in the reactor (2) and a energy balance in the jacket (3). Variable and parameter values are given in Table 1 . The dynamics related to the jacket temperature can be considered to be much faster than that related to the reactor temperature, thus the jacket time constant is negligible. Therefore $\mathrm{T}_{\mathrm{j}}$ can be calculated by the algebraic Eq. (4)

$$
\mathrm{T}_{\mathrm{j}}=\frac{\rho_{\mathrm{j}} \mathrm{C}_{\mathrm{pj}} \cdot \mathrm{F}_{\mathrm{j}} \cdot \mathrm{T}_{\mathrm{j} 0}+\mathrm{UA} \cdot \mathrm{T}}{\rho_{\mathrm{j}} \mathrm{C}_{\mathrm{pj}} \cdot \mathrm{F}_{\mathrm{j}}+\mathrm{UA}}
$$

A simplified model with two equations in $C_{a}$ and $T$ can be derived substituting $T_{j}$, given by Eq. (4), into Eq. (2).

In order to generalise the mathematical model of the reactor, Eqs. (1), (2) and (4) can be expressed in a dimensionless way, leading to the following state-space model:

$$
\begin{aligned}
& \frac{\mathrm{dx}_{2}}{\mathrm{~d} \tau}=\frac{\mathrm{x}_{60}}{\mathrm{x}_{1}}\left(\mathrm{x}_{20}-\mathrm{x}_{2}\right)-\mathrm{c}_{0} \mathrm{x}_{2} \cdot \mathrm{e}^{-1 / \mathrm{x}_{3}} \\
& \frac{\mathrm{dx}_{3}}{\mathrm{~d} \tau}=\frac{\mathrm{x}_{60}}{\mathrm{x}_{1}}\left(\mathrm{x}_{30}-\mathrm{x}_{3}\right)+\mathrm{c}_{1} \mathrm{x}_{2} \cdot \mathrm{e}^{-1 / \mathrm{x}_{3}}-\frac{\mathrm{c}_{2} \mathrm{c}_{3} \mathrm{x}_{5} \cdot\left(\mathrm{x}_{3}-\mathrm{x}_{40}\right)}{\mathrm{x}_{1}\left(\mathrm{c}_{3} \mathrm{x}_{5}+\mathrm{c}_{4}\right)}
\end{aligned}
$$

The definition of the dimensionless variables is given in Table 2 and a more detailed description can be found in the work of Perez and Albertos [39].

\section{Analysis of the reactor dynamics}

It is well known that an exothermic CSTR without control can have multiple steady states and bifurcations [2,39]. This can lead to difficulties in the design of a controller. Using the dimensionless Eqs. (5) and (6) a thorough analysis of CSTR dynamics was carried out with the aim of allowing to choose a suitable control configuration and to design the controllers. For the system under study the bifurcation parameter is the coolant flow rate of the CSTR jacket (dimensionless parameter $x_{5}$ ). In Fig. 1 the continuity diagram $x_{3}$ (dimensionless reactor temperature) vs $x_{5}$ is shown. In the diagram it is possible to identify three regions: a higher and a lower branch (continuous line) characterized by stable points and one region (dashed line) in the middle characterized by instability.

Let us suppose that the initial state of the reactor corresponds to point $\mathrm{A}\left(x_{3}=0.0443 ; x_{5}=1.50\right)$. Following a little change in the bifurcation parameter (from $x_{5}=1.50$ to $x_{5}=1.54$ ) the system moves from a stable region to an unstable region 
Table 1

Variables, nominal operating conditions and parameter values.

\begin{tabular}{lll}
\hline Variable & Description & Value \\
\hline$C_{\mathrm{a}}$ & Reactant concentration of the outlet stream $\left(\mathrm{kmol} \mathrm{A} / \mathrm{m}^{3}\right)$ & \\
$F$ & Volumetric flow rate of the outlet stream $\left(\mathrm{m}^{3} / \mathrm{h}\right)$ & \\
$F_{\mathrm{j}}$ & Volumetric flow rate of the cooling water $\left(\mathrm{m}^{3} / \mathrm{h}\right)$ & \\
$F_{\mathrm{o}}$ & Volumetric flow rate of the inlet stream $\left(\mathrm{m}^{3} / \mathrm{h}\right)$ & \\
$T$ & Reactor temperature $(\mathrm{K})$ & \\
$T_{\mathrm{j}}$ & Jacket temperature $(\mathrm{K})$ & 23.22 \\
$V$ & Reactor volume $\left(\mathrm{m}^{3}\right)$ & 8 \\
$A$ & Heat transfer area $\left(\mathrm{m}^{2}\right)$ & 3.92 \\
$C_{\mathrm{ao}}$ & Reactant concentration inlet stream $\left(\mathrm{kmol} \mathrm{A} / \mathrm{m}^{3}\right)$ & 3.13 \\
$C_{\mathrm{aor}}$ & Initial reactant concentration $\left(\mathrm{kmol} \mathrm{A} / \mathrm{m}^{3}\right)$ & 4.18 \\
$C_{\mathrm{p}}$ & Heat capacity of inlet and outlet streams $(\mathrm{kJ} / \mathrm{kg} \mathrm{K})$ & 69815 \\
$C_{\mathrm{pj}}$ & Heat capacity of cooling water $(\mathrm{kJ} / \mathrm{kg} \mathrm{K})$ & 1.4130 \\
$E$ & Activation energy $(\mathrm{kJ} / \mathrm{kmol})$ & 1.13 \\
$F_{\mathrm{js}}$ & Steady state volumetric flow rate of cooling water $\left(\mathrm{m}^{3} / \mathrm{h}\right)$ & 69815 \\
$F_{\mathrm{os}}$ & Volumetric flow rate of inlet stream $\left(\mathrm{m}^{3} / \mathrm{h}\right)$ & 8.314 \\
$H$ & Enthalpy of reaction $(\mathrm{kJ} / \mathrm{kmol})$ & 309.9 \\
$R$ & Perfect gas constant $(\mathrm{kJ} / \mathrm{kmol} \mathrm{K)}$ & 294.7 \\
$T_{\mathrm{r}}$ & Set point temperature $(\mathrm{K})$ & 294.7 \\
$T_{\mathrm{o}}$ & Inlet stream temperature $(\mathrm{K})$ & 3065 \\
$T_{\mathrm{jo}}$ & Inlet stream cooling water temperature $(\mathrm{K})$ & 0.085 \\
$U$ & Overall heat transfer in the jacket $\left(\mathrm{kJ} /\left(\mathrm{h} \mathrm{m} \mathrm{m}^{2} \mathrm{~K}\right)\right)$ & 1.36 \\
$V_{\mathrm{j}}$ & Jacket volume $\left(\mathrm{m}^{3}\right)$ & $7.08 \times 10^{10}$ \\
$V_{\mathrm{s}}$ & Steady state reactor volume $\left(\mathrm{m}^{3}\right)$ & 1000 \\
$\alpha$ & Preexponential factor from Arrhenius law $\left(\mathrm{h}^{-1}\right)$ & \\
$\rho$ & Density of the inlet and outlet streams $\left(\mathrm{kg} / \mathrm{m}^{3}\right)$ & \\
$\rho_{\mathrm{j}}$ & Density of cooling water $\left(\mathrm{kg} / \mathrm{m}^{3}\right)$ & \\
\hline & & \\
\hline & & \\
\hline
\end{tabular}

Table 2

Dimensionless variables.

\begin{tabular}{llll}
\hline $\begin{array}{l}\text { Dimensionless } \\
\text { variable }\end{array}$ & Definition & $\begin{array}{l}\text { Dimensionless } \\
\text { variable }\end{array}$ & Definition \\
\hline$\tau$ & $\mathrm{F}_{\mathrm{os}} \cdot \mathrm{t} / \mathrm{V}_{\mathrm{s}}$ & $\mathrm{c}_{0}$ & $\mathrm{~V}_{\mathrm{s}} \cdot \alpha / \mathrm{F}_{\mathrm{os}}$ \\
$x_{1}$ & $\mathrm{~V} / \mathrm{V}_{\mathrm{s}}$ & $\mathrm{c}_{1}{ }^{*}$ & $\mathrm{~V}_{\mathrm{s}} \cdot \alpha \cdot \mathrm{H} \cdot \mathrm{R} \cdot \mathrm{C}_{\mathrm{aor}}$ \\
$x_{2}$ & $\mathrm{C}_{\mathrm{a}} / \mathrm{C}_{\mathrm{aor}}$ & $\mathrm{c}_{11^{*}}$ & $\mathrm{~F}_{\mathrm{os}} \cdot \rho \cdot \mathrm{c}_{\mathrm{p}} \cdot \mathrm{E}$ \\
$x_{3}$ & $\mathrm{R} \cdot \mathrm{T} / \mathrm{E}$ & $\mathrm{c}_{1}$ & $\mathrm{c}_{1}{ }^{*} / \mathrm{c}_{11}{ }^{*}$ \\
$x_{5}$ & $\mathrm{~F}_{\mathrm{j}} / \mathrm{F}_{\mathrm{js}}$ & $\mathrm{c}_{2}$ & $\mathrm{U} \cdot \mathrm{A} / \rho \cdot \mathrm{c}_{\mathrm{p}} \cdot \mathrm{F}_{\mathrm{os}}$ \\
$x_{20}$ & $\mathrm{C}_{\mathrm{ao}} / \mathrm{C}_{\mathrm{aor}}$ & $\mathrm{c}_{3}$ & $\mathrm{~V}_{\mathrm{s}} \cdot \mathrm{F}_{\mathrm{js}} / \mathrm{F}_{\mathrm{os}} \cdot \mathrm{V}_{\mathrm{j}}$ \\
$x_{30}$ & $\mathrm{R} \cdot \mathrm{T}_{\mathrm{o}} / \mathrm{E}$ & $\mathrm{c}_{4}{ }^{*}$ & $\rho \cdot \mathrm{c}_{\mathrm{p}} \cdot \mathrm{V}_{\mathrm{s}} / \rho_{\mathrm{j}} \cdot \mathrm{c}_{\mathrm{pj}} \cdot \mathrm{V}_{\mathrm{j}}$ \\
$x_{40}$ & $\mathrm{R} \cdot \mathrm{T}_{\mathrm{jo}} / \mathrm{E}$ & $\mathrm{c}_{4}$ & $\mathrm{c}_{4}{ }^{*} \cdot \mathrm{c}_{2}$ \\
$x_{60}$ & $\mathrm{~F}_{\mathrm{o}} / \mathrm{F}_{\mathrm{os}}$ & & \\
\hline
\end{tabular}

(position B). The Hopf bifurcation point (H) and the lower limit point (LP) [3,12] bound the unstable region. In Fig. 2 the change with time of the dimensionless reactor temperature $x_{3}$, after a step change in $x_{5}$ from 1.50 to 1.54 at $\tau=10$ is reported. The reactor temperature $x_{3}$ oscillates with increasing amplitude until it reaches a constant oscillation amplitude: the reactor moves from the stable region to the unstable region (from A to B in the continuity diagram of Fig. 1) [37].

The phase state diagram of Fig. $3, x_{3}$ vs $x_{2}$, instead shows the three equilibrium points corresponding to the bifurcation parameter value $x_{5}=1.54$ seen in Fig. 2 . The equilibrium points, indicated by white dots, correspond, from right to left respectively, to a stable node, an unstable saddle node and an unstable focus surrounded by a stable limit cycle (respectively points $\mathrm{P}_{1}, \mathrm{P}_{2}, \mathrm{P}_{3}$ shown in Fig. 1 ).

Fig. 4 shows the effects that the variations of two additional variables, $x_{60}$ and $x_{30}$, can have on the reactor temperature. As it can be seen a change in one or both variables modifies the bifurcation diagram $x_{3}$ vs $x_{5}$ of Fig. 1 . The curve obtained at $x_{60}=1.5$ and $x_{30}=0.037$ (the line in bold) corresponds to the initial stable condition of the reactor. The horizontal line indicates the desired dimensionless temperature of the reactor $\left(x_{3}=0.0369\right.$, the value which would be chosen as set-point in a feedback temperature control loop). By increasing $x_{30}$ to 0.038 , the initial curve shifts to the right and the CSTR remains in the stable region. A fall in $x_{30}$ to 0.0353 moves the curve to the left and the CSTR into the unstable region (the horizontal line now crosses the dashed line of the new curve). A way of controlling the system in this unstable region is to use a traditional feedback controller, that manipulates the coolant flow rate, with a high proportional gain. However experience has shown that this solution is not acceptable in real systems since it would result in noise amplification and instability. A second and preferable method, as demonstrated further on, is to manipulate a second process variable such as the inlet flow rate of the CSTR, $x_{60}$, in a feedforward control loop in which the input temperature $x_{30}$ is measured. 


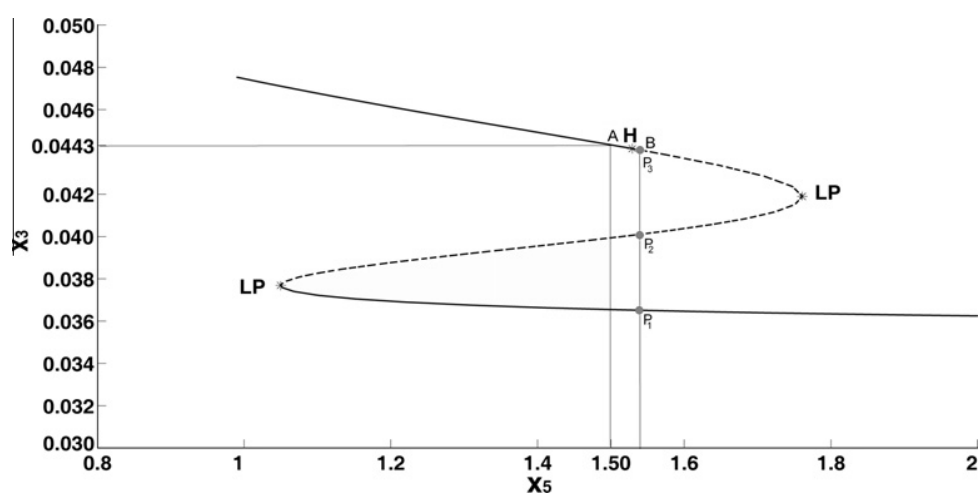

Fig. 1. Dimensionless bifurcation plot $x_{3}$ vs $x_{5}$.

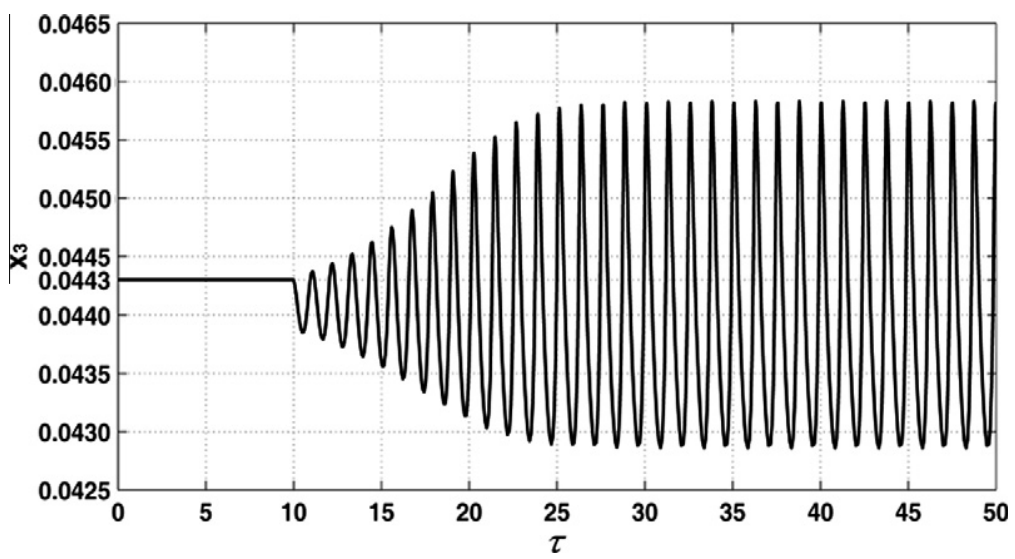

Fig. 2. Uncontrolled system simulation with a change from $x_{5}=1.50$ to $x_{5}=1.54$ (from the stable position A to unstable position B of the continuity diagram of Fig. 2).

By manipulating $x_{60}$ it is in fact possible to shift the unstable region of the equilibrium curve over the set-point value, maintaining the system in a stable region, without oscillations.

By reducing $x_{60}$ from 1.5 to 0.75 the system in fact can be seen to move back into the stable region (out of the dashed line of the new curve corresponding to $x_{60}=0.75$ and $x_{30}=0.0353$ ).

\section{Type-2 fuzzy logic}

\subsection{Type-2 fuzzy sets}

Here only the essential part of type-2 fuzzy sets and logic is presented. A more detailed introduction can be found in [14,23].

A type-2 fuzzy set $\widetilde{A}[22]$ is defined as:

$$
\widetilde{A}=\int_{\mathrm{x} \in \mathrm{X}} \int_{\mathrm{u} \in \mathrm{J}_{\mathrm{X}}} \mu_{\tilde{\mathrm{A}}}(\mathrm{x}, \mathrm{u}) /(\mathrm{x}, \mathrm{u}) \quad J_{x} \subseteq[0,1]
$$

in which $0 \leqslant \mu_{A}(x, u) \leqslant 1$ is a type-2 membership function, $x \in X$ and $u \in J_{x} \subseteq[0,1]$, while the primary membership of $\mathrm{x}$ is the domain of the secondary membership function.

In this paper only a particular case of type-2 fuzzy sets is treated: the interval type-2 fuzzy sets (IT2FS) [5]. An interval type-2 fuzzy set $\widetilde{A}_{\mathrm{I}}$ is defined as:

$$
\widetilde{A}_{\mathrm{I}}=\int_{\mathrm{x} \in \mathrm{X}}\left[\int_{\mathrm{u} \in \mathrm{J}_{\mathrm{x}}}\left(\frac{1}{\mathrm{u}}\right)\right] / \mathrm{x} \quad J_{\mathrm{x}} \subseteq[0,1]
$$

Uncertainty in a fuzzy system may arise for several reasons [26]. A generalized theory of uncertainty has been recently introduced by Zadeh [47]. All the uncertainties present in a system can be modelled in the shape and in the position 


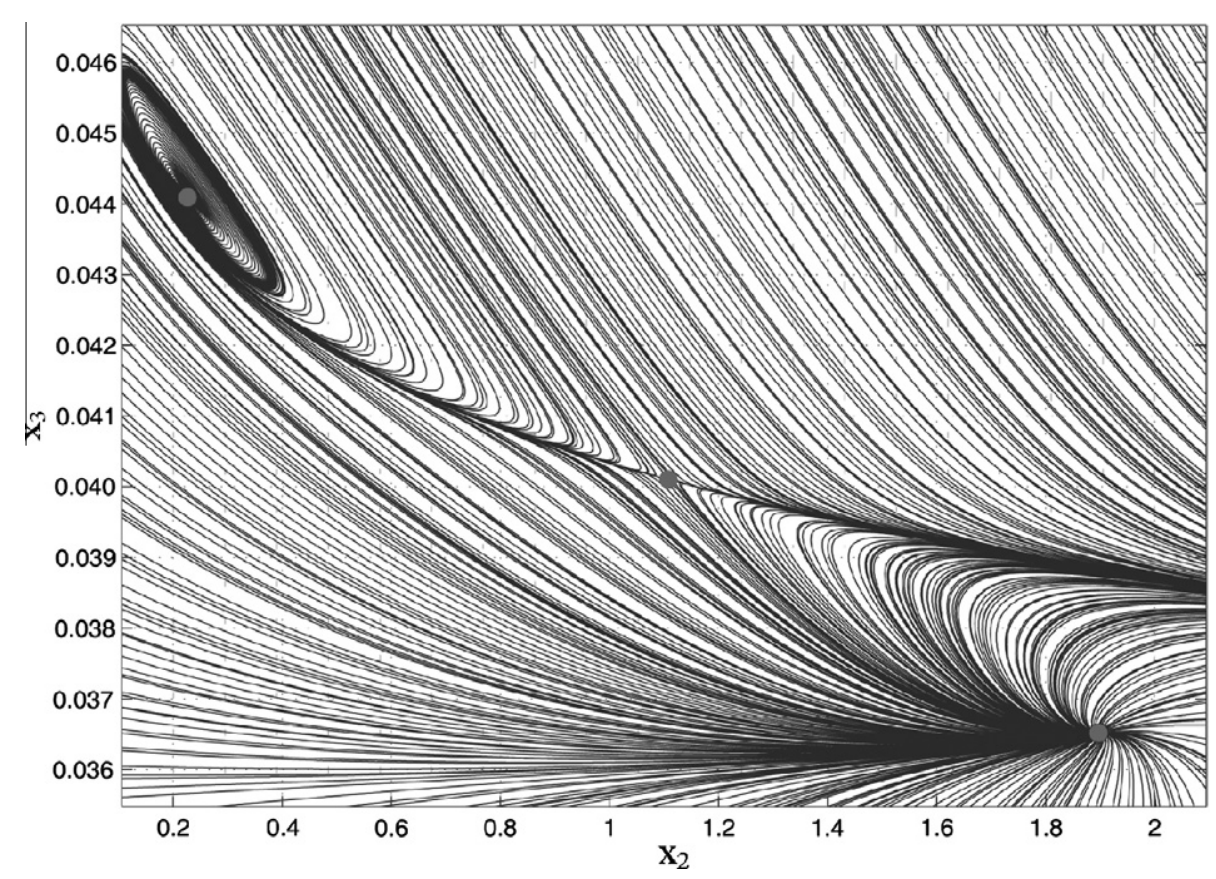

Fig. 3. Phase state diagram $x_{3}$ vs $x_{2}$ at $x_{5}=1.54$.

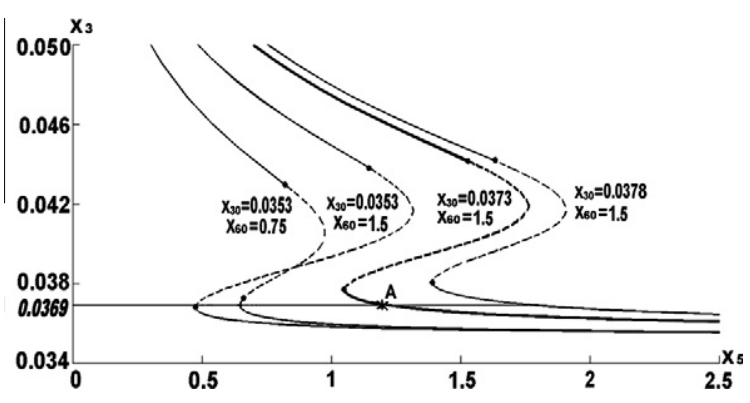

Fig. 4. Dimensionless bifurcation plot $x_{3}$ vs $x_{5}$ with changing parameters values $x_{30}$ and $x_{60}$.

using the FOU [34]: it represents the entire interval type-2 fuzzy set and its shading denotes interval sets for the secondary membership functions. For computing reasons it can be described in terms of upper and lower membership functions (Fig. 5) [21].

If type-1 fuzzy logic systems are unable to directly handle uncertainties, type-2 fuzzy logic systems result to be very useful in all circumstances where measurements are characterized by uncertainty and the choice of an exact membership function is difficult.

\subsection{Type-2 fuzzy logic systems}

As any type-1 Fuzzy Logic System (FLS), also a type-2 FLS contains four components: a fuzzifier, a rule-base, an inferenceengine and an output-processor [9,35]. The main difference between type- 2 and type- 1 FLSs is the output-processor, in fact for a type-1 FLS it is just the defuzzifier, while, for a type-2 FLS it contains two components: the type-reducer, that maps a type-2 fuzzy set into a type- 1 fuzzy set, and a second component, a normal defuzzifier, that transforms a fuzzy output into a crisp output $[7,26]$. In Fig. 6 a general type-2 FLS is depicted.

The rules of a type-2 FLS have the same structure of a type-1 FLS, the only difference consisting in the nature of membership functions. The lth rule has in fact the following form:

$$
\mathrm{R}^{l}: \mathrm{IF} x_{1} \text { is } \widetilde{F}_{1}^{l} \text { and } \ldots . \text { and } x_{\mathrm{p}} \text { is } \widetilde{F}_{p}^{l} \text { THEN } y \text { is } \widetilde{G}^{l} l=1, \ldots, M
$$

The inference mechanism combines the rules (9) of the type-2 FLS as follows: 


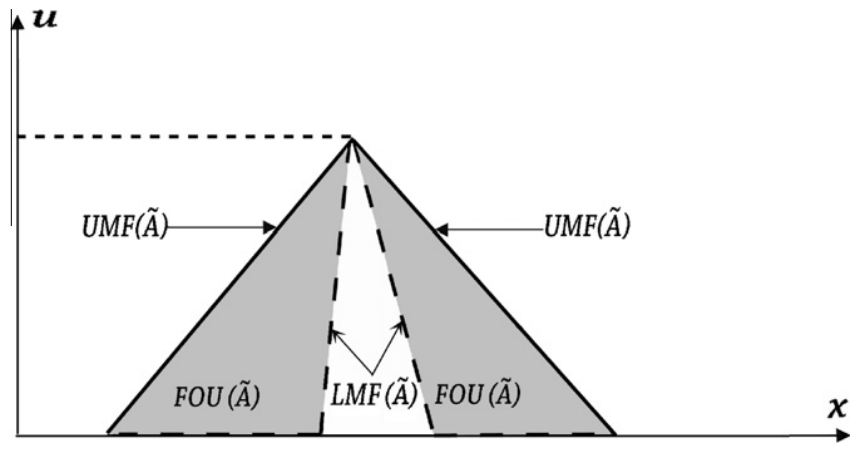

Fig. 5. FOU (Shaded), LMF (dashed), UMF (Solid) for IT2FS $\widetilde{A}$.

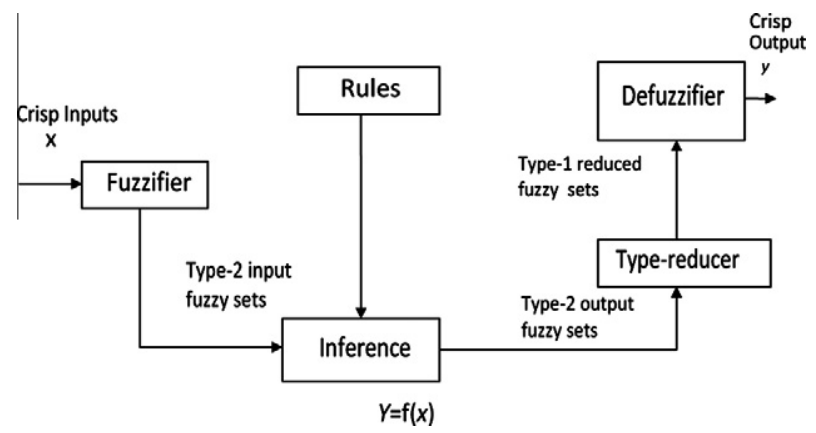

Fig. 6. Type-2 FLS.

$$
\begin{aligned}
& \mathrm{R}^{l}: \widetilde{F}_{1}^{l} \times \cdots \times \widetilde{F}_{p}^{l} \rightarrow \widetilde{G}^{l}=\widetilde{A}^{l} \rightarrow \widetilde{G}^{l} \quad l=1, \ldots, M \\
& \mu_{R^{l}}(\bar{x}, y)=\mu_{\widetilde{A}^{l} \circ \widetilde{G}^{l}}(\bar{x}, y)=\mu_{\widetilde{F_{1}^{l}}}\left(x_{1}\right) \Pi \cdots \Pi \mu_{\widetilde{F}_{p}^{l}}\left(x_{p}\right) \Pi \mu_{\widetilde{G}_{p}^{l}}(y)
\end{aligned}
$$

giving a mapping from input to output type-2 fuzzy sets. Each rule $R^{l}$ determines a type-2 fuzzy set $\widetilde{B}^{l}$, for instance as a Cartesian product $\widetilde{B}^{l}=\widetilde{A}_{x} \circ R^{l}$, the membership of which is defined as:

$$
\mu_{\widetilde{B}^{l}}(y)=\mu_{\tilde{A}_{x} \circ R^{l}}=\coprod_{x \in X}\left[\mu_{\widetilde{A}_{x l}^{l}}(\bar{x}) \prod \mu_{R^{l}}(\bar{x}, y)\right] y \in Y \quad l=1, \ldots, M
$$

where the membership function of the type- 2 fuzzy set $\widetilde{A}_{x}$ is:

$$
\mu_{\hat{A}_{x}}(\bar{x})=\mu_{\tilde{x}_{1}}\left(x_{1}\right) \Pi \cdots \Pi \mu_{\tilde{x}_{p}^{l}}\left(x_{p}\right)=\Pi_{i=1}^{p} \mu_{\tilde{x}_{p}^{l}}\left(x_{i}\right)
$$

As far as the type-reduction is concerned many methods can be considered, among which the center of sets type reducer [19] is one of the most used. It can be expressed as:

$$
Y_{\cos }(x)=\int_{\mathbf{y}^{1} \in\left[y_{l}^{1}, y_{\mathrm{r}}^{1}\right]} \cdots \int_{\mathrm{y}^{\mathrm{M}} \in\left[\mathrm{y}_{l}^{\mathrm{M}}, y_{\mathrm{r}}^{\mathrm{M}}\right]} \int_{\mathrm{f}^{1} \in\left[\mathbb{[}^{1}, \overline{\mathrm{f}}^{1}\right]} \ldots \int_{\left.f^{\mathrm{M}} \in \underline{-}_{-}^{\mathrm{f}, \overline{\mathrm{M}}]}\right]} 1 /\left(\frac{\sum_{\mathrm{i}=1}^{\mathrm{M}} \mathrm{f}^{\mathrm{i}} \mathrm{y}^{\mathrm{i}}}{\sum_{\mathrm{i}=1}^{\mathrm{M}} \mathrm{f}^{\mathrm{i}}}\right)
$$

In (14) $Y_{\cos }(\mathbf{x})$ is an interval set and is computed with Karnik-Mendel iterative method [23,24], while $y_{l}$ and $y_{r}$ are its endpoints, $\left[f_{\underline{f}}^{i}, \bar{f}^{i}\right]$ and $\left[\underline{y_{l}^{i}}, y_{r}^{i}\right]$ are respectively the interval firing level of the $i$ th rule and the centroid of the type- 2 interval consequent set.

Since $Y_{\cos }(\mathrm{x})$ is an interval type-2 fuzzy set the defuzzified output is the average of $y_{l}$ and $y_{r}$ :

$$
y(x)=\frac{y_{l}+y_{r}}{2}
$$

\subsection{Stability analysis}

The stability of fuzzy control systems is one of the more controversial aspects of fuzzy control. The absence of standard procedures for the analysis of stability is one of the main criticisms of fuzzy control detractors. Actually several stability 
analysis methods have been proposed for type-1 fuzzy control systems. A good covering of them can be found in Kandel, Luo and Zang [20].

The design of stable type-2 fuzzy controllers, based on the application of the Lyapunov method was proposed by Castillo, Aguilar, Cazarez-Castro and Cardenas [8] for controllers with state variables as inputs.

The stability analysis of the type-2 fuzzy control system designed for the non-isothermal CSTR considered in this study, that uses the error and the integral of error as inputs of the feedback controller, is addressed using a different original approach based on the knowledge of the process dynamics obtained by the continuity diagrams. Each continuity diagram considers the equilibrium points when a single bifurcation parameter is changed. In particular the main continuity diagram represents the equilibrium values of the output variable versus the manipulative variable. For each disturbance it is possible to obtain a family of continuity diagrams and verify that the manipulative variable is able to keep the process in a stable equilibrium point. If not and if another manipulative variable is available it is possible to design a feedforward control loop that allows to keep the process in stable equilibrium points for the full range of the disturbance.

The application of the approach was carried out in Section 3 (Figs. 1 and 4) for the case of disturbances in the input temperature of the CSTR.

Similar considerations can be made for parameter variations; for each of them the variation range for which the process can be maintained in a stable condition can be determined.

\section{Control configuration}

The control objective for the CSTR under study is to keep the reactor temperature at a desired value despite the presence of disturbances like load changes or parameter variations.

Two main problems must be dealt with: the existence of bifurcation points and the uncertainty in the knowledge of some parameters. The solution of the first problem can be found in the choice of a suitable control configuration like the feedbackfeedforward control described in Section 3, while the use of type-2 FLCs allows an effective control even when some parameters take on values that are very different compared to the ones considered for the controller design.

As previously shown the reactor temperature can start to oscillate and become unstable when there are load or parameter changes. In some cases the choice of only a feedback control loop for the reactor temperature, using the coolant flow rate as manipulative variable, does not allow to reach the control objective since the presence of bifurcations results in the loss of stability as in the case of the negative step change in the inlet temperature, illustrated in Figs. 1-3.

The addition of a feedforward controller activated by the measurement of the input temperature $\left(x_{30}\right)$ and manipulating the input flow rate $\left(x_{60}\right)$, allows to keep the reactor far from bifurcation points and therefore from unstable conditions.

The study of the dynamics of the reactor carried out by simulation indicated that there are no other critical conditions and that also with changes, of reasonable size, of all the other known disturbances, the described mixed feedback-feedforward control system is able to keep the reactor in the stable region. If the reactor is required to work in a larger operative region more than one feedforward controller might be necessary.

\subsection{Implementation of fuzzy logic controllers}

The proposed control configuration was implemented by simulation using type-1 FLCs and type-2 FLCs [8] for the feedback and the feedforward loop in order to test the ability of type-2 FLCs to manage the situations in which parameter variations do not allow to keep the reactor in the stable region.

In order to fully compare type-1 FLCs with type-2 FLCs uncertainty was introduced in the system changing a number of parameters from constant to random values.

All feedback FLCs use two input variables, error (e) and integral error (inte), and one output variable ( $x_{5}$ ) with a TISO (two inputs - single output) structure. The structure of the feedforward FLC is instead SISO (single input-single output) and is much simpler, consisting of only two membership functions and two rules.

The shape of membership functions was selected among Gaussian, triangular and trapezoidal shapes by minimizing the Integral Square Error $\left(\mathrm{ISE}=\int_{0}^{\infty}[e(t)]^{2} d t\right)$ index. Firstly Gaussian, triangular and trapezoidal type- 1 fuzzy sets were compared choosing as simulation environment the system without uncertainties specified in Section 6. The ISE index at $\tau=180$ was lower for the Gaussian shape (ISE $=10 \times 10^{-5}$ ) (Fig. 16) than for the triangular $\left(\right.$ ISE $=11.8 \times 10^{-5}$ ) or trapezoidal shape $\left(\right.$ ISE $\left.=12.2 \times 10^{-5}\right)$.

The amplitude value of the Gaussian membership functions for the error and the integral of the error type- 1 fuzzy sets was then selected minimizing the ISE index as well. The centres of membership functions were equally distanced.

The amplitudes of internal and external membership functions were assumed constant for all type- 2 membership functions and symmetrical with respect to the corresponding type- 1 membership functions.

As for type-1 fuzzy sets the amplitude values were chosen minimizing the ISE index.

Therefore both type- 1 and type- 2 feedback FLCs use seven Gaussian membership functions for each variable, with a normalized range between $[-1,1]$ and the Sugeno inference method [43] with constant output. The fuzzy sets of type- 1 and type- 2 feedback FLCs are shown in Figs. 7 and 8 respectively, while the fuzzy sets of type- 1 and type-2 feedforward FLCs are shown in Figs. 9 and 10 respectively. 


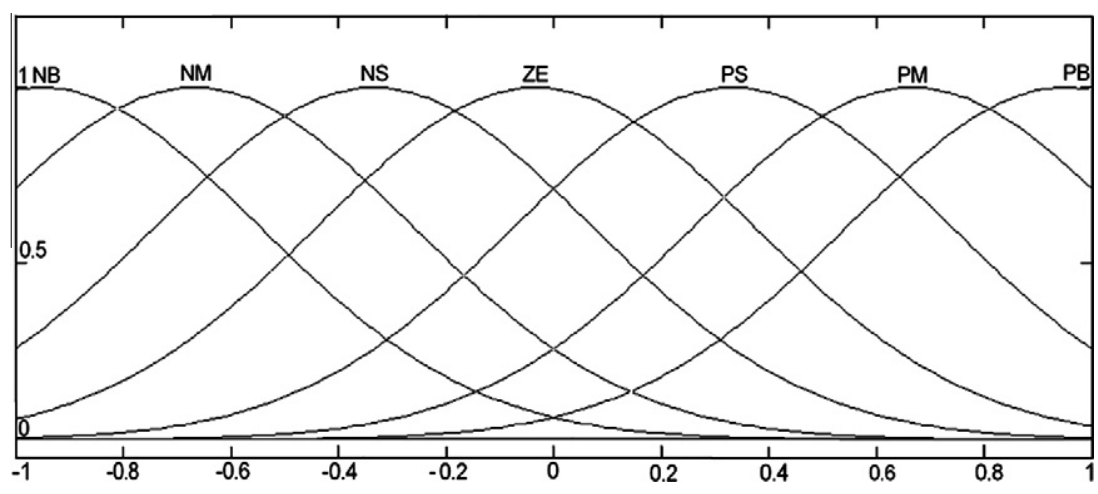

Fig. 7. Type-1 membership functions for "error" and "int-error" of feedback control.

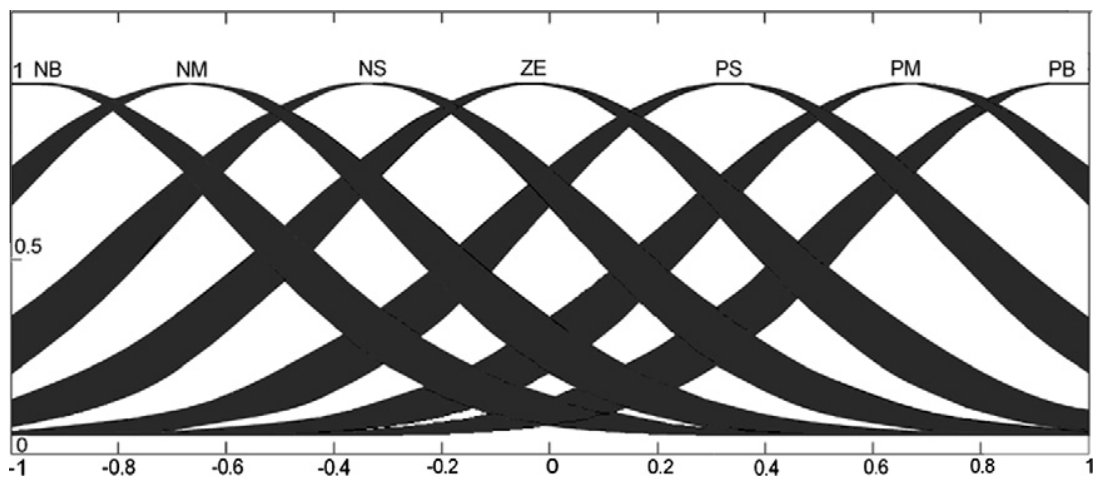

Fig. 8. Type-2 membership functions for "error" and "int-error" of feedback control.

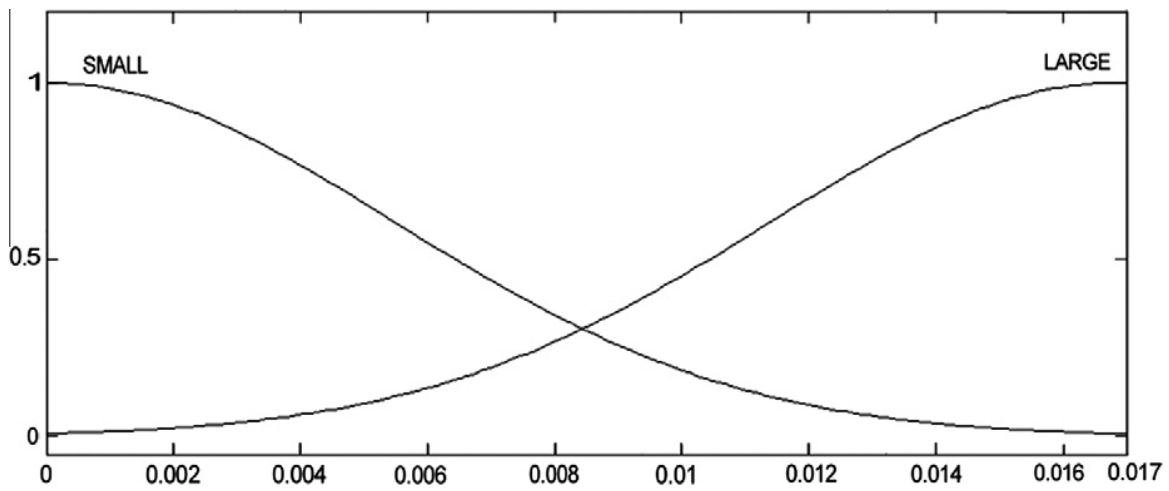

Fig. 9. Type-1 membership functions for feedforward control.

The rule base used in the feedback FLCs was designed by simulation runs, starting out from a symmetrical rule base and making modifications where necessary. The best results were obtained using the rule base shown in Table 3 .

To make a fair comparison type- 1 and type-2 FLCs have the same structure (same operative range, rules, membership functions layout, Sugeno outputs, gain and integral actions), with the only difference regarding the amplitude of Gaussian membership functions. Each type-1 Gaussian membership function has an amplitude value that is the average of type- 2 internal and external Gaussian membership function amplitude values.

Although the above procedure does not allow to obtain optimal type- 1 and type- 2 controllers, that is not the aim of the paper, nevertheless its application to both type- 1 and type- 2 controllers leads to comparable sub-optimal controllers. An optimization procedure based for instance on the use of genetic algorithms could be also considered. 


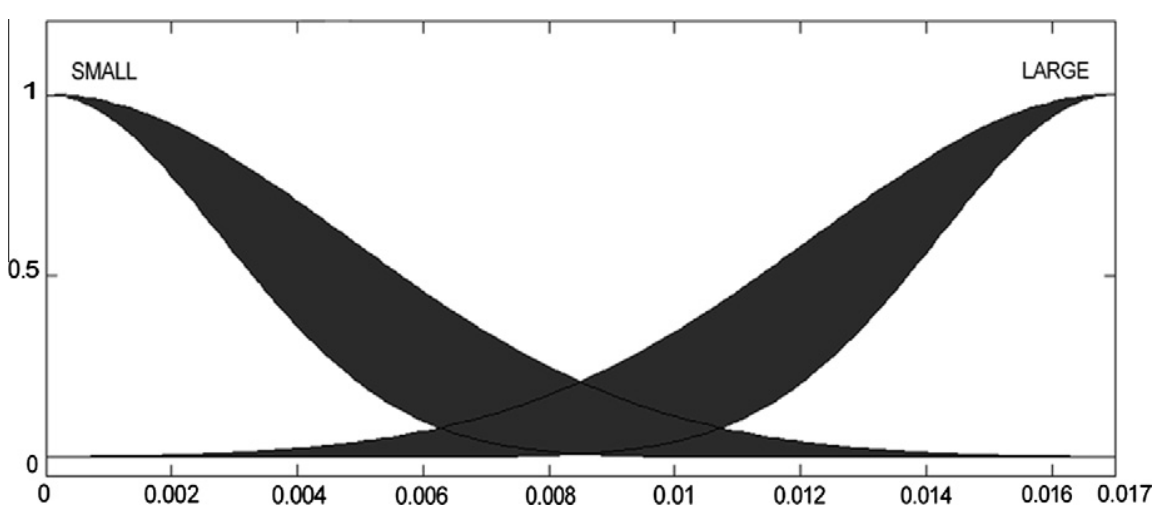

Fig. 10. Type-2 membership functions for feedforward control.

Table 3

Feedback type- 1 and type-2 FLC rules.

\begin{tabular}{lllllll}
\hline Error & Int-error & & & & & \\
\cline { 2 - 6 } & NB & NM & NS & ZE & PS & PM \\
\hline NB & NB & NB & NB & NM & NS & NS \\
NM & NB & NM & NM & NM & NS & ZE \\
NS & NB & NM & NS & NS & ZE & PS \\
ZE & NB & NM & NS & ZE & PS & PM \\
PS & NM & NS & ZE & PS & PS \\
PM & NS & ZE & PS & PM & PM & PM \\
PB & ZE & PS & PS & PM & PB \\
\hline
\end{tabular}

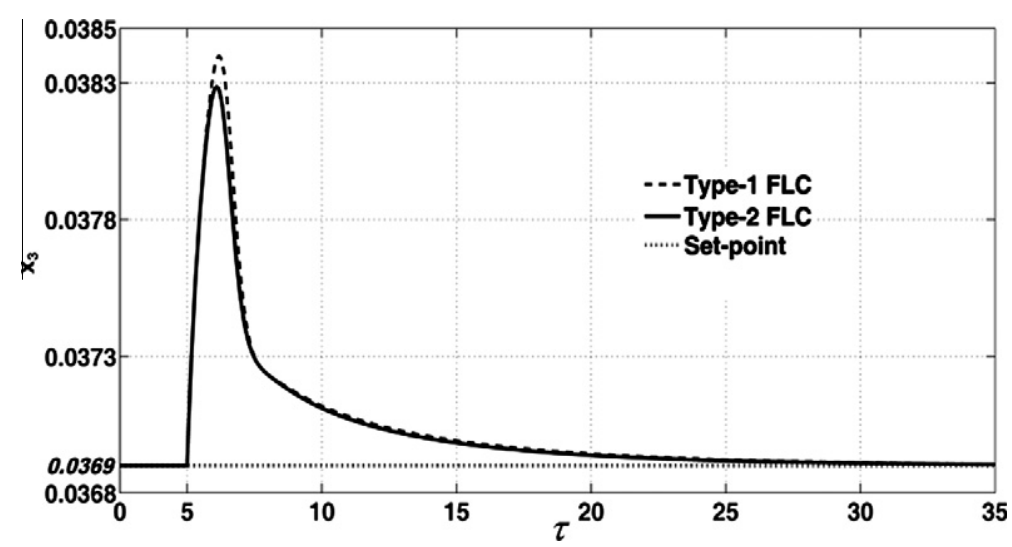

Fig. 11. Response of dimensionless temperature $x_{3}$ with type- 1 and type- 2 fuzzy feedback control, to a step in the dimensionless disturbance from $x_{30}=0.037$ to $x_{30}=0.038$ at $\tau=5$ and set-point $=0.0369$.

Type-2 FLCs were basically implemented using the software made available on line by Mendel [36], integrating in a Matlab function, to be used in Simulink, the fuzzy sets definition data, the inference mechanism and the type-reducer mechanism.

\section{Results and discussion}

Simulations were firstly carried out using only feedback controllers and keeping all the parameters of the reactor model constant. The response of the reactor temperature to a step change in the inlet temperature $\left(x_{30}\right)$ at $\tau=5$, while maintaining a constant temperature $\left(x_{3}\right)$ set-point, is shown Fig. 11. It can be seen that the response obtained with the two controllers is very similar, in terms of overshooting and response time. 


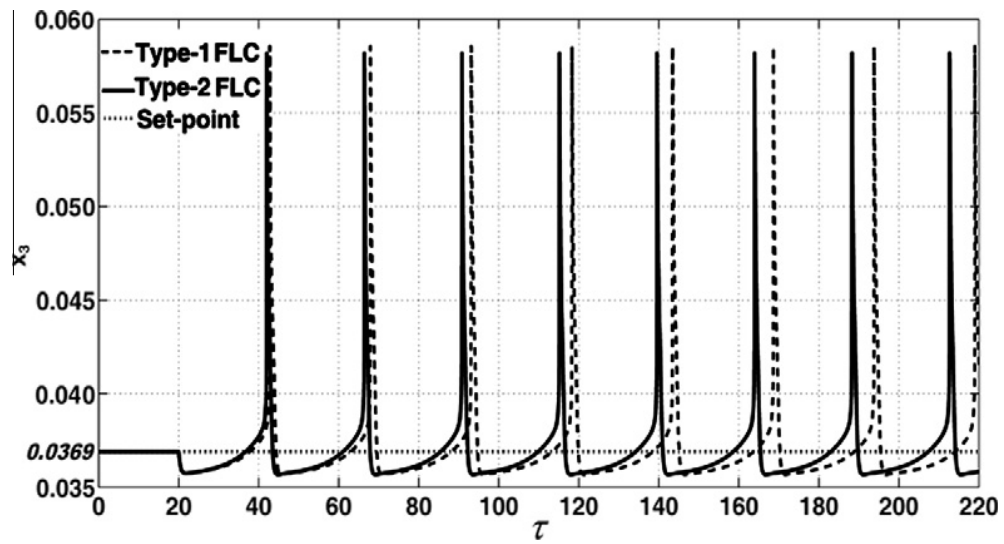

Fig. 12. Response of dimensionless temperature $x_{3}$ with type- 1 and type- 2 fuzzy feedback control, to a step in the dimensionless disturbance from $x_{30}=0.037$ to $x_{30}=0.0353$ at $\tau=20$ and set-point $=0.0369$.

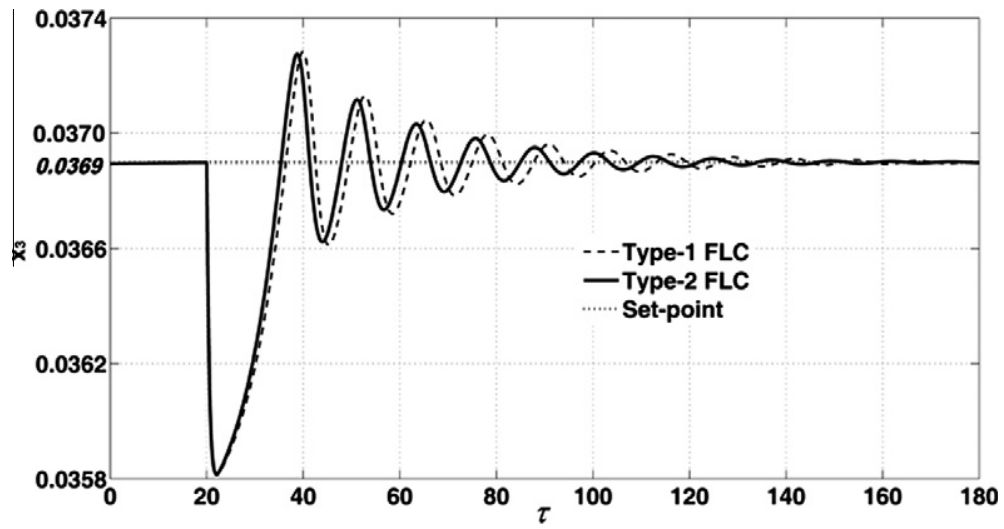

Fig. 13. Response of dimensionless temperature $x_{3}$ with type- 1 and type- 2 fuzzy feedback-feedforward control, to a step in the dimensionless disturbance from $x_{30}=0.037$ to $x_{30}=0.0353$ at $\tau=20$ and set-point $=0.0369$.

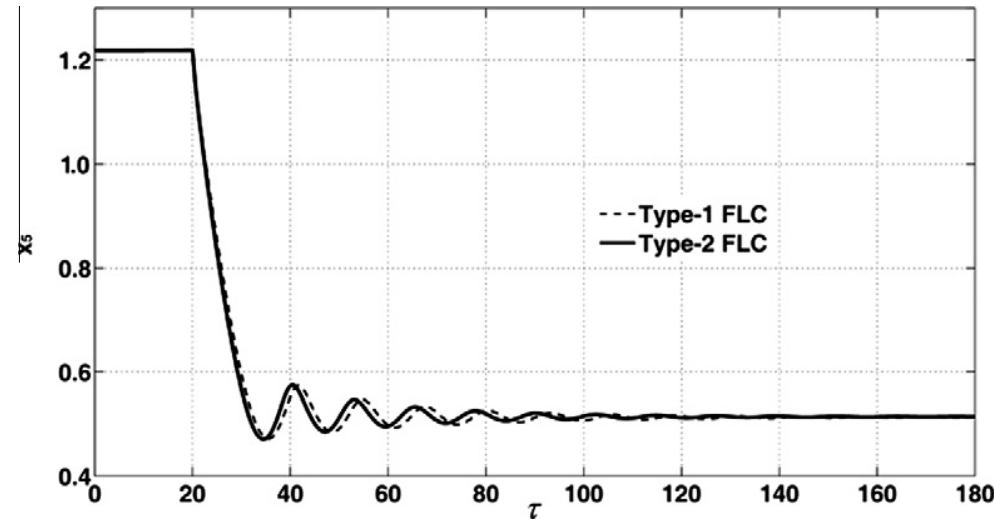

Fig. 14. Dimensionless dilution rate $x_{5}$ with type- 1 and type- 2 fuzzy feedback-feedforward control following a step in the dimensionless disturbance from $x_{30}=0.037$ to $x_{30}=0.0353$ at $\tau=20$ and set-point $=0.0369$.

Maintaining the same set-point and introducing a step change of $x_{30}$ in the opposite direction the CSTR enters into the unstable region and the response with both fuzzy controllers can be seen to oscillate around the set-point value $=0.0369$ (Fig. 12). 


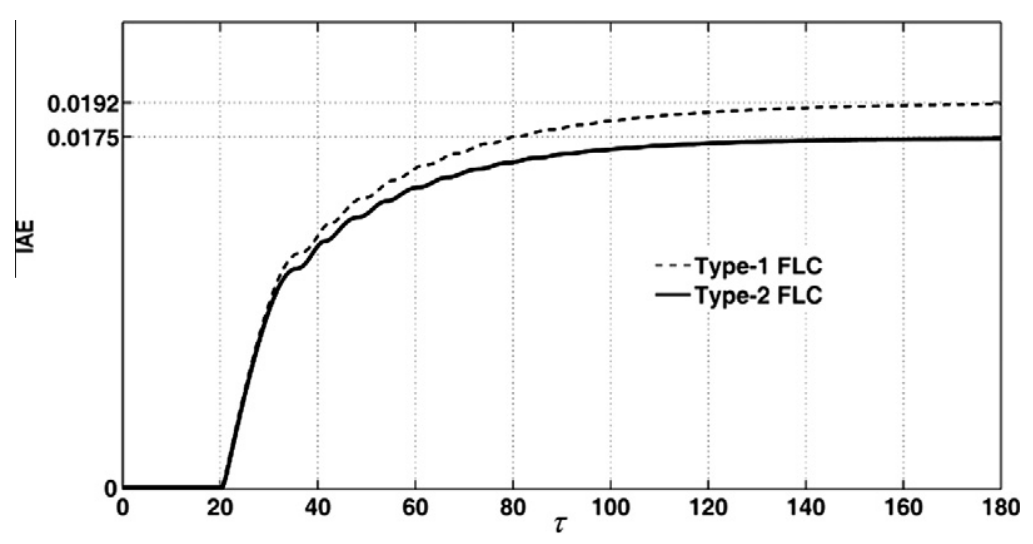

Fig. 15. IAE for type- 1 and type- 2 fuzzy feedback-feedforward control. Constant set-point 0.0369 , step in the dimensionless disturbance from $x_{30}=0.037$ to $x_{30}=0.0353$ at $\tau=20$.

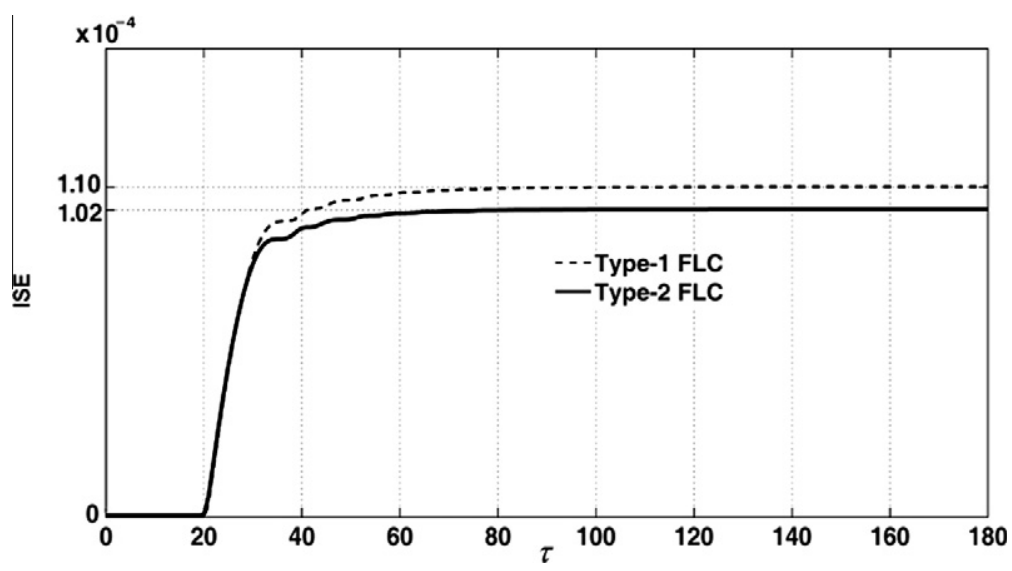

Fig. 16. ISE for type- 1 and type- 2 fuzzy feedback-feedforward control. Constant set-point 0.0369 , step in the dimensionless disturbance from $x_{30}=0.037$ to $x_{30}=0.0353$ at $\tau=20$.

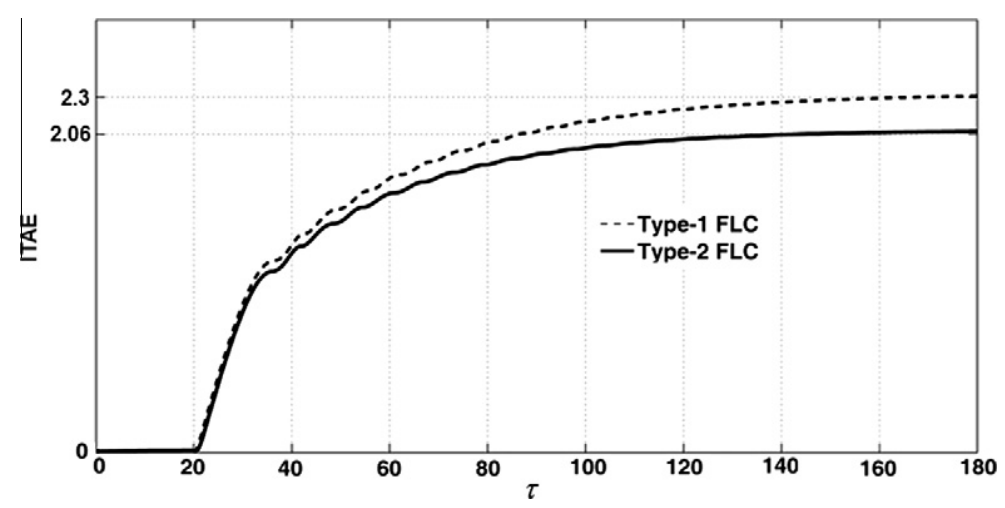

Fig. 17. ITAE for type- 1 and type- 2 fuzzy feedback-feedforward control. Constant set-point 0.0369 , step in the dimensionless disturbance from $x_{30}=0.037$ to $x_{30}=0.0353$ at $\tau=20$.

The response is unacceptable for effective control and suggests the use of a feedforward controller.

Figs. 13 and 14 show the simulation results, in terms of controlled temperature $x_{3}$ and manipulation variable $x_{5}$ respectively, obtained after the introduction of the feedforward controller in each fuzzy control system for the same conditions of the simulation shown in Fig. 12. 


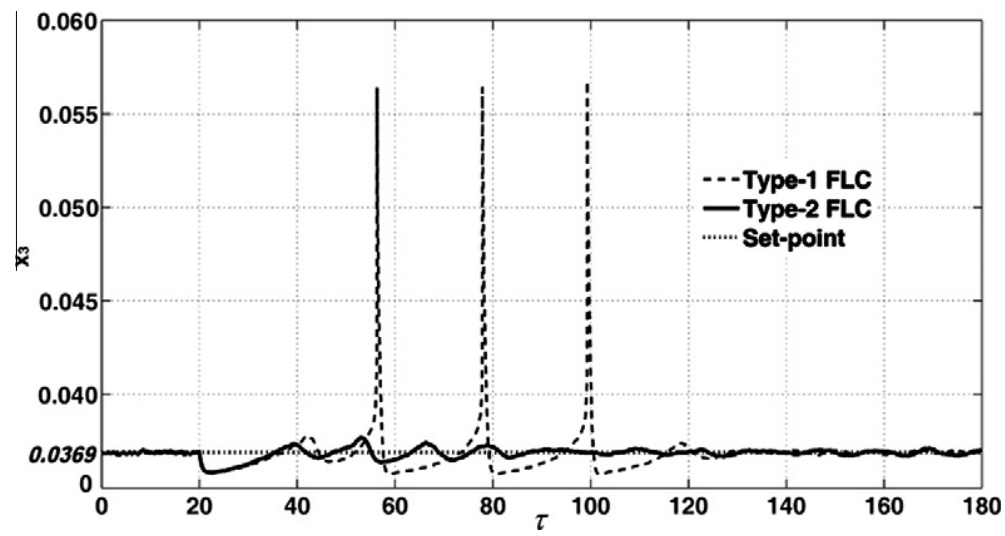

Fig. 18. Response of dimensionless temperature $x_{3}$ with type- 1 and type- 2 fuzzy feedback-feedforward control and random variation of system parameters and noise in the measurement of the controlled variable $x_{3}$. Constant set-point 0.0369 , step in the dimensionless disturbance $x_{30}$ from $x_{30}=0.037$ to $x_{30}=0.0353$ at $\tau=20$.

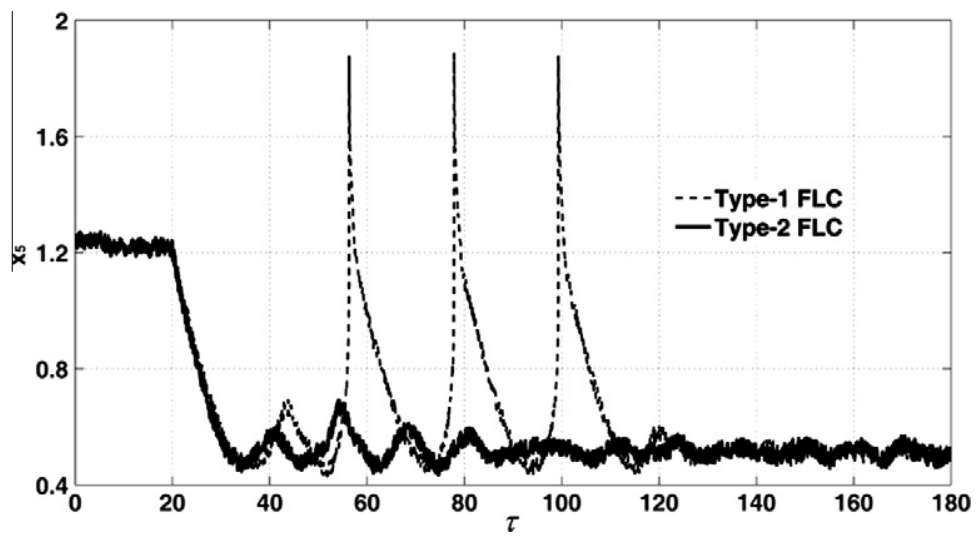

Fig. 19. Behaviour of the manipulative variable $x_{5}$ with type- 1 and type- 2 fuzzy feedback-feedforward control and random variation of system parameters and noise in the measurement of the controlled variable $x_{3}$. Constant set-point 0.0369 , step in the dimensionless disturbance $x_{30}$ from $x_{30}=0.037$ to $x_{30}=0.0353$ at $\tau=20$.

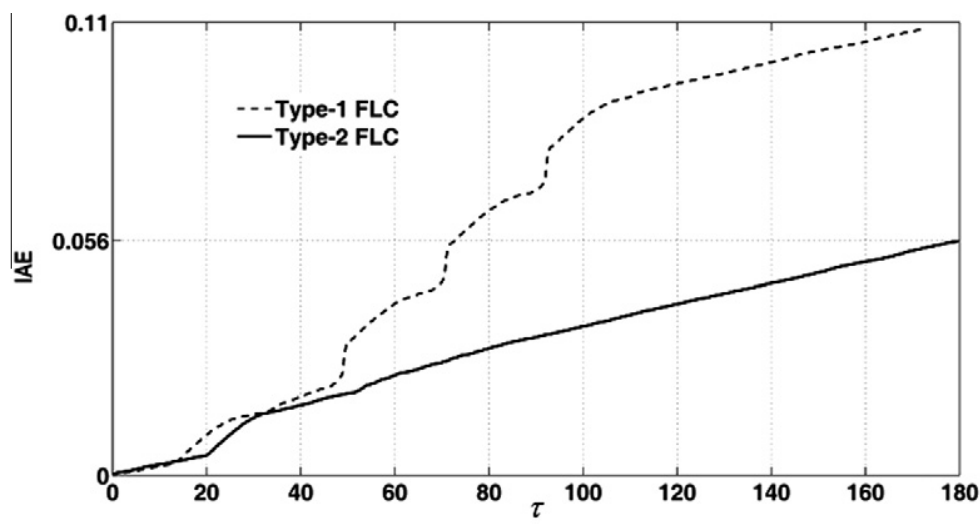

Fig. 20. IAE for type- 1 and type- 2 fuzzy feedback=-feedforward control. Constant set-point 0.0369 , step in the dimensionless disturbance $x_{30}$ from $x_{30}=0.037$ to $x_{30}=0.0353$ at $\tau=20$, random variation of system parameters and noise in the measurement of the controlled variable $x_{3}$.

The new value of $x_{5}$ reached by the control system can be read in the continuity diagram of Fig. 4 looking at the equilibrium curve obtained for $x_{30}=0.0353$ and $x_{60}=0.75$. 


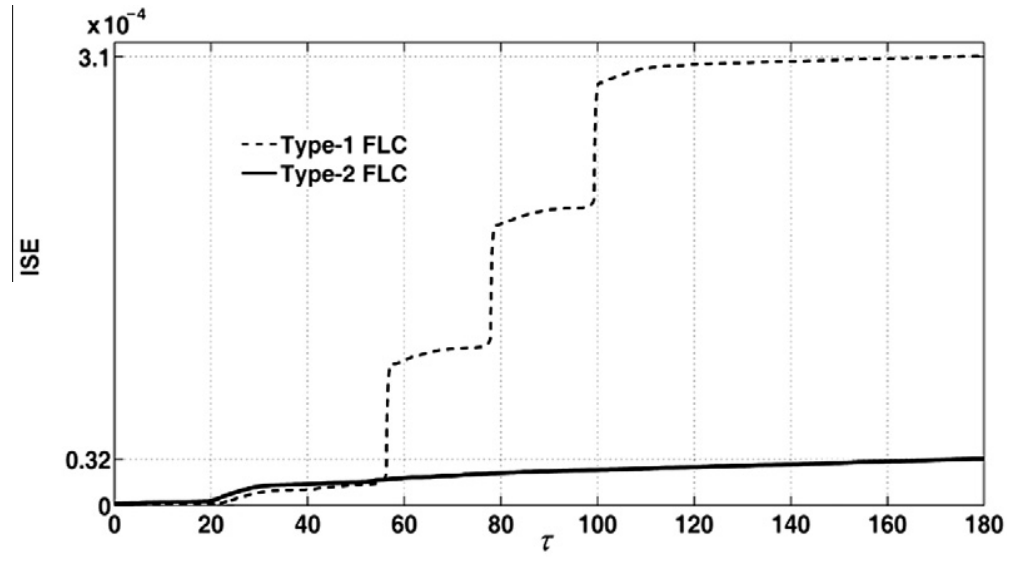

Fig. 21. ISE for type- 1 and type- 2 fuzzy feedback-feedforward control. Constant set-point 0.0369 , step in the dimensionless disturbance $x_{30}$ from $x_{30}=0.037$ to $x_{30}=0.0353$ at $\tau=20$, random variation of system parameters and noise in the measurement of the controlled variable $x_{3}$.

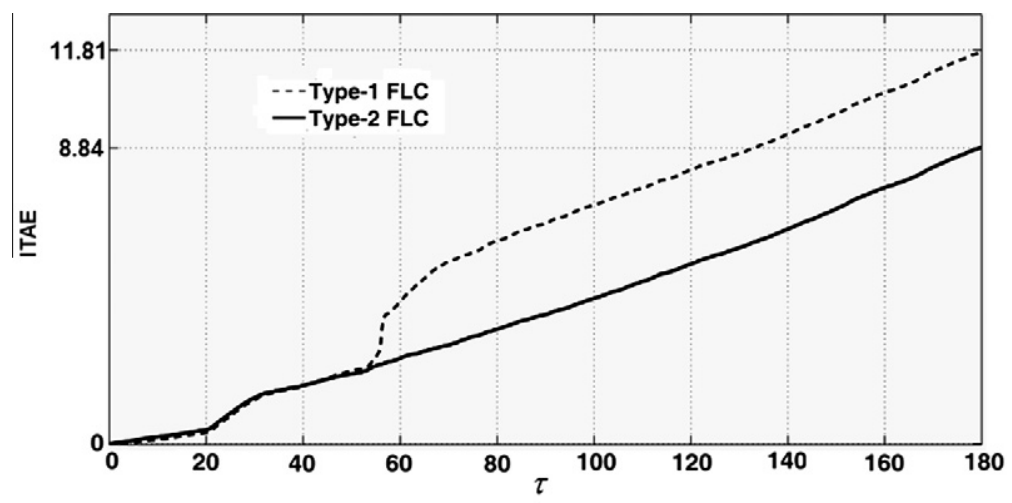

Fig. 22. ITAE for type- 1 and type- 2 fuzzy feedback-feedforward control. Constant set-point 0.0369 , step in the dimensionless disturbance $x_{30}$ from $x_{30}=0.037$ to $x_{30}=0.0353$ at $\tau=20$, random variation of system parameters and noise in the measurement of the controlled variable $x_{3}$.

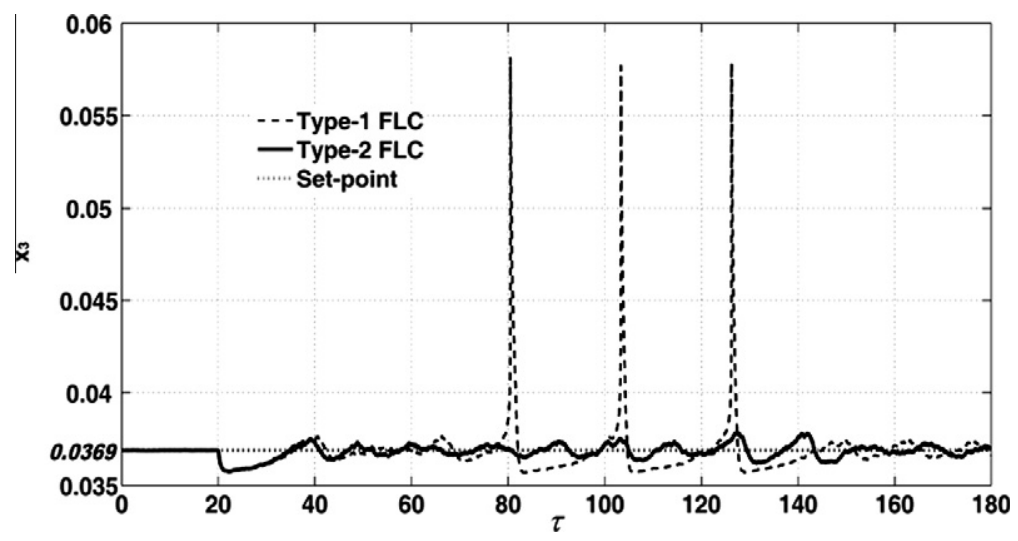

Fig. 23. Response of dimensionless temperature $x_{3}$ with type- 1 and type- 2 fuzzy feedback-feedforward control and noise in the measurement of the disturbance $x_{30}$ in the feedforward control loop. Constant set-point 0.0369 , step in the dimensionless disturbance $x_{30}$ from $x_{30}=0.037$ to $x_{30}=0.0353$ at $\tau=20$.

The response of the type-2 FLC slightly outperforms that of the type-1 FLC. The responses with both controllers start to oscillate around the set point value after the introduction of the step change at $\tau=20$ with decreasing amplitude until the set point value is reached. The oscillations with the type-2 FLC are slightly smaller than those with the type-1 FLC and the set point is reached in a shorter time. 


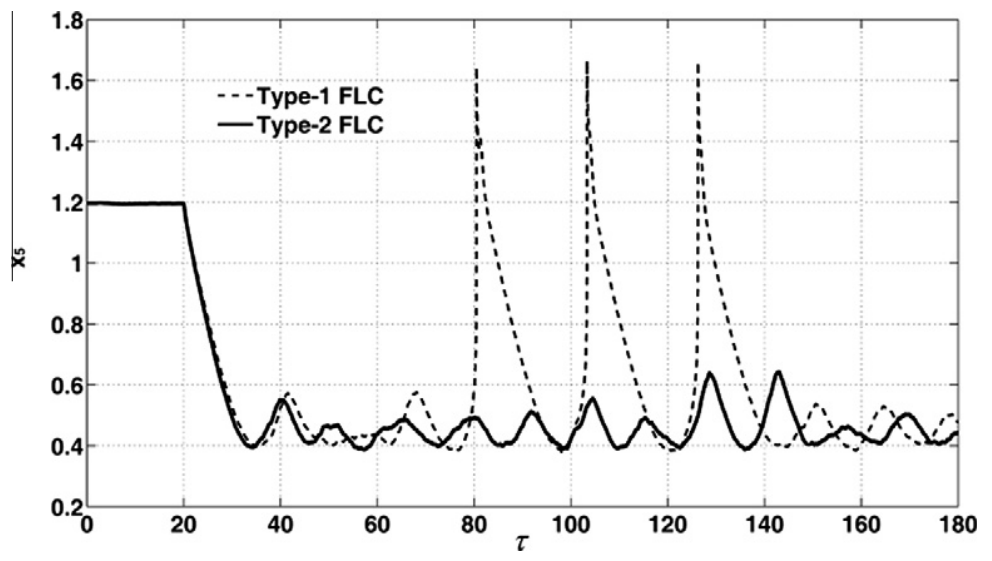

Fig. 24. Behaviour of the manipulative variable $x_{5}$ with type- 1 and type- 2 fuzzy feedback-feedforward control and noise in the measurement of the disturbance $x_{30}$ in the feedforward control loop. Constant set-point 0.0369 , step in the dimensionless disturbance $x_{30}$ from $x_{30}=0.037$ to $x_{30}=0.0353$ at $\tau=20$.

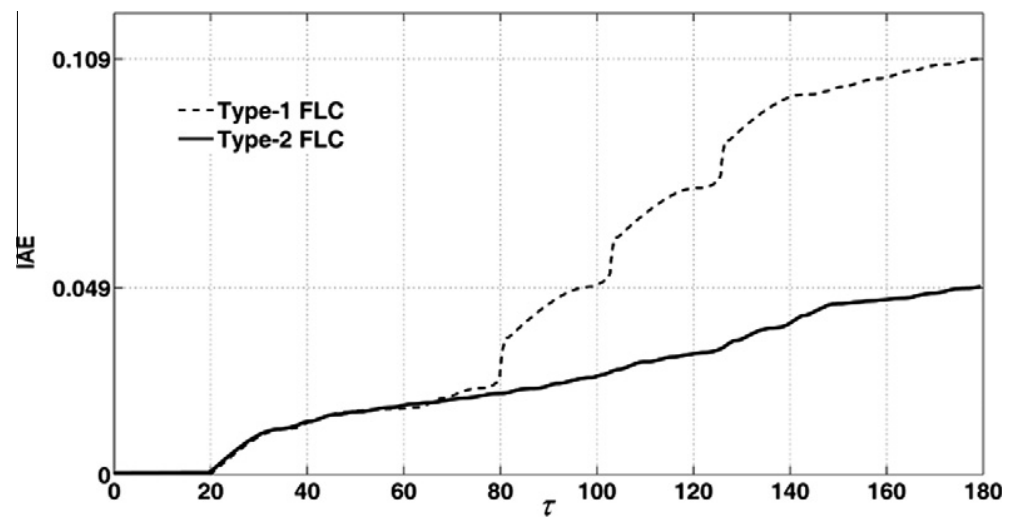

Fig. 25. IAE for type- 1 and type- 2 fuzzy feedback-feedforward control and noise in the measurement of the disturbance $x_{30}$ in the feedforward control loop. Constant set-point 0.0369 , step in the dimensionless disturbance $x_{30}$ from $x_{30}=0.037$ to $x_{30}=0.0353$ at $\tau=20$.

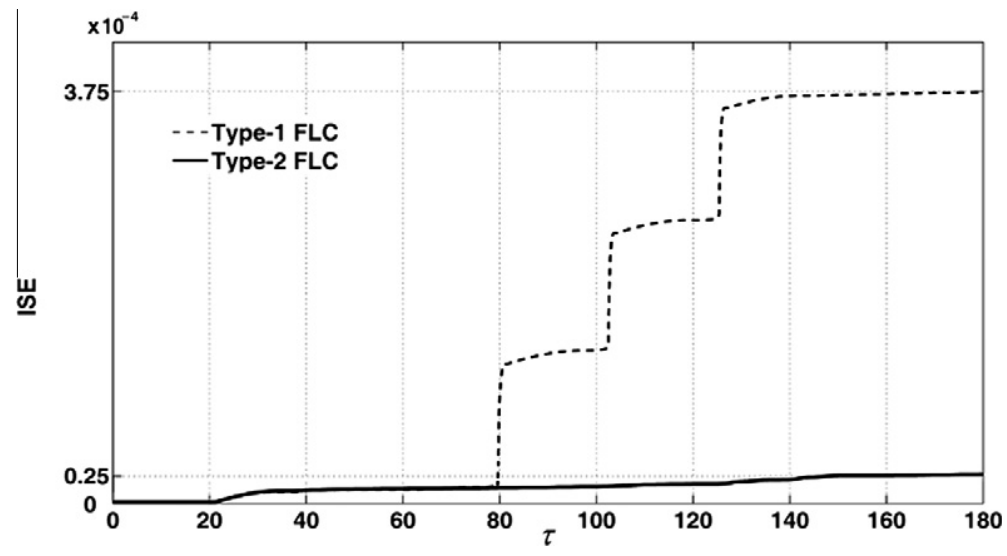

Fig. 26. ISE for type- 1 and type- 2 fuzzy feedback-feedforward control and noise in the measurement of the disturbance $x_{30}$ in the feedforward control loop. Constant set-point 0.0369 , step in the dimensionless disturbance $x_{30}$ from $x_{30}=0.037$ to $x_{30}=0.0353$ at $\tau=20$.

The Integral Absolute Error $\left(\operatorname{IAE}=\int_{0}^{\infty}|e(t)| d t\right)$, the ISE and the Integral of Time and Absolute Error $\left(\operatorname{ITAE}=\int_{0}^{\infty}|e(t)| t d t\right)$ were calculated in order to evaluate the performance of type- 1 and type-2 fuzzy control systems (Figs. 15-17). 


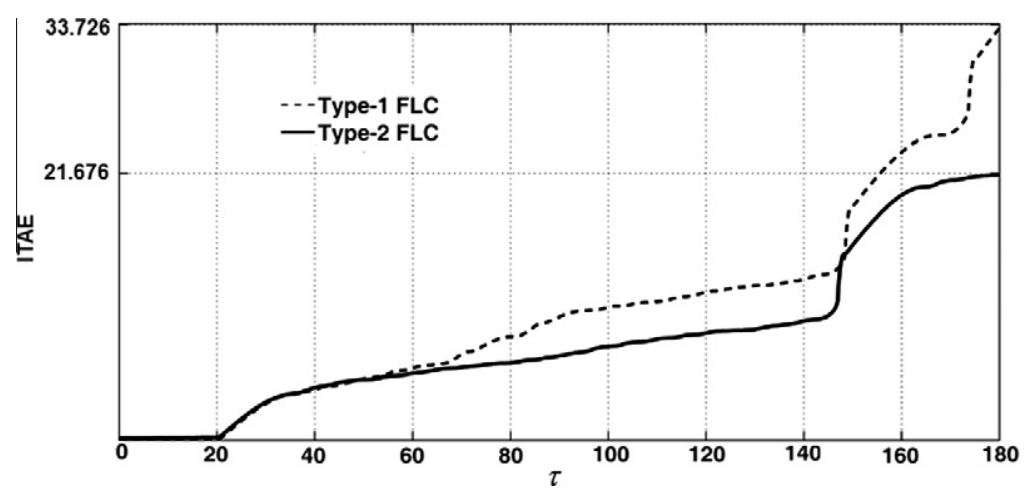

Fig. 27. ITAE for type-1 and type-2 fuzzy feedback-feedforward control and noise in the measurement of the disturbance $x_{30}$ in the feedforward control loop. Constant set-point 0.0369 , step in the dimensionless disturbance $x_{30}$ from $x_{30}=0.037$ to $x_{30}=0.0353$ at $\tau=20$.

Table 4

Average performance indexes (at $\tau=180$ ) with parameter changes and measurement noise.

\begin{tabular}{llll}
\hline & Average ISE & Average ITAE & Average IAE \\
\hline Type-1 feedback FLC & $3.08 \times 10^{-4}$ & 11.60 & $10.9 \times 10^{-2}$ \\
Type-2 feedback FLC & $0.3225 \times 10^{-4}$ & 8.88 & $5.635 \times 10^{-2}$ \\
Type-1 mixed feedback-feedforward FLC & $3.786 \times 10^{-4}$ & 33.73 & 0.110 \\
Type-2 mixed feedback-feedforward FLC & $0.25 \times 10^{-4}$ & 21.685 & 0.0502 \\
\hline
\end{tabular}

Figs. 15-17 show that IAE, ISE and ITAE values are very similar for type-1 and type-2 FLCs. Since type-1 FLCs can have difficulties in minimizing the effects of uncertainties in the plant model, we would expect that the type- 2 FLC gives better results when model parameter uncertainties or noise are present. This is confirmed by Figs. 18-22 in which the simulation results obtained when uncertainties were introduced as random variations of some system parameters and as a noise in the measurement of the controlled variable $x_{3}$ are reported. The results refer to one of 20 simulation runs in which $c_{0}$ and $c_{2}$ were randomly changed with a standard deviation of $5 \%$ of their design value. The noise introduced in the measurement is a white noise corresponding to $\pm 2 \%$ of the normalized reference temperature. The type- 2 FLC clearly has the best performance.

Both fuzzy controllers show a good performance, but the type- 2 FLC outperforms its type- 1 counterpart, reducing the amplitude of oscillations more than the type-1 FLC and minimizing the effects of the uncertainties present in the system. Notice the high peaks present in the responses with the type- 1 controller. IAE, ISE and ITAE performance indexes, shown in Figs. 20-22, also confirm the better performance of the type-2 FLC.

Figs. 23-27 show the behaviour of the mixed feedback-feedforward control system when the source of uncertainty is a noise in the measurement of the disturbance $x_{30}$, in the feedforward control loop. Also in this case the results concern one of 20 simulation runs in which $c_{0}$ and $c_{2}$ were randomly changed with a standard deviation of $5 \%$ of their design value. The noise introduced in the disturbance measurement is a white noise corresponding to $\pm 2 \%$ of the normalized design value. It is evident, observing Figs. 23 and 24, the superiority of the type-2 FLC in reducing the amplitude of temperature oscillations and quickly reaching the set-point value. The type-1 FLC instead is not able to handle the uncertainty, since the temperature oscillates with constant amplitude. Also the IAE, ISE and ITAE indexes, shown in Figs. 25-27, confirm the results of Figs. 23 and 24. In Table 4 the average errors obtained in the 20 simulation runs for the feedback and the mixed feedbackfeedforward stucture are reported.

\section{Conclusions}

In this paper a mixed feedback-feedforward control configuration and type-2 fuzzy logic controllers were considered for the temperature control of a non-isothermal CSTR, presenting bifurcations, parameter variations and uncertainty in variable measurements.

The proposed control configuration is based on the knowledge of the complex dynamics of the uncontrolled system. The results of simulations show that the non-linearities present in the system can be better handled rather than using the feedback control only. The feedforward control loop allows in fact to maintain the effective control of the reactor in the presence of disturbances that would lead the reactor to an unstable region.

With the use of type-2 FLCs it is possible to obtain a robust control system when parameter uncertainties and measurement noise are present. The comparison with the results obtained using the same control configuration but with type-1 FLCs shows a better performance of type-2 FLCs. 
The simulation results show that the proposed control configuration with type-2 FLCs can be an effective solution to a very difficult control problem and an alternative to the use of adaptive controllers.

\section{References}

[1] A. Al-khazraji, N. Essounbouli, A. Hamzaoui, F. Nollet, J. Zaytoon, Type-2 fuzzy sliding mode control without reaching phase for nonlinear system, Eng. Appl. Artif. Intell. 24 (2011) 23-38.

[2] N.R. Amundson, R. Aris, An analysis of chemical reactor stability and control-1: the possibility of local control, with perfect or imperfect control mechanisms, Chem. Eng. Sci. 7 (1958) 121-131.

[3] B.W. Bequette, Process Dynamics: Modeling Analysis and Simulation, Prentice Hall, New Jersey, 1998. pp. 388-392.

[4] P.A.S. Birkin, J.M. Garibaldi, A comparison of type-1 and type-2 fuzzy controllers in a micro-robot context, in: Proc. Fuzz-IEEE, Korea, 2009, pp. 18571862.

[5] J. Cao, H. Liu, P. Li, D. Brown, Adaptive fuzzy logic controller for vehicle active suspension with interval type-2 fuzzy membership functions, in: FUZZIEEE, Hong Kong, 2008, pp. 83-89.

[6] N.R. Cazarez-Castro, L.T. Aguilar, O. Castillo, Fuzzy logic control with genetic membership function parameters optimization for the output regulation of a servomechanism with nonlinear backlash, Expert Syst. Appl. 37 (2010) 4368-4378.

[7] O. Castillo, G. Huesca, F. Valdez, Evolutionary computing for optimizing type-2 fuzzy systems in intelligent control of non-linear dynamic plants, in: Proceedings of North American Fuzzy Information Processing Society (NAFIPS), Ann Arbor, MI, 2005, pp. 247-251.

[8] O. Castillo, L.T. Aguilar, N.R. Cazarez-Castro, S. Cardenas, Systematic design of a stable type-2 fuzzy logic controller, J. Appl. Soft Comput. Inform. Control 8 (2008) 1274-1279.

[9] O. Castillo, P. Melin, A new approach for plant monitoring using type-2 fuzzy logic and fractal theory, Int. J. General Syst. 33 (2004) 305-319.

[10] O. Castillo, R. Martínez-Marroquín, P. Melin, F. Valdez, J. Soria, Comparative study of bio-inspired algorithms applied to the optimization of type-1 and type-2 fuzzy controllers for an autonomous mobile robot, Inform. Sci. (2010), doi:10.1016/j.ins.2010.02.022.

[11] N.R. Cazarez-Castro, O. Castillo, L.T.Aguilar, S.L. Cardenas, From type-1 to type-2 fuzzy logic control: a stability and robustness study, in: International Congress on Fuzzy logic, Neural Networks and Genetic Algorithms, P. Melin, O. Castillo, eds, Tijuana, Mexico, 2005, pp. 308-321.

[12] M. Cibrario and J. Lévine, Saddle-node bifurcation control with application to thermal runaway of continuous stirred tanks reactors, in: Proceedings 30th IEEE Conference on Decision and Control, Brighton, England, 1991, pp.1551-1552.

[13] M. Galluzzo, B. Cosenza, A. Matharu, Control of a nonlinear continuous bioreactor with bifurcation, by a type-2 fuzzy logic controller, Comput. Chem. Eng. 32 (2008) 2986-2993.

[14] M. Galluzzo, B. Cosenza, Control of the biodegradation of mixed wastes in a continuous bioreactor by a type-2 fuzzy logic controller, Comput. Chem. Eng. 33 (2009) 1475-1483.

[15] H. Hagras, A type-2 fuzzy logic controller for autonomous mobile robots, in: Proceedings of the IEEE International Conference on Fuzzy Systems, Budapest, Hungary, 2004, pp. 965-970.

[16] H. Hagras, Type-2 FLCs: a new generation of fuzzy controllers, IEEE Comput. Intell. Mag. 2 (2007) 30-44.

[17] H. Hagras, Type-2 fuzzy logic controllers: a way forward for fuzzy systems in real world environments, Lect. Notes Comput. Sci. 5050 (2008) 181-200.

[18] J. Hale, H. Kocak, Dynamics and Bifurcations, Springer-Verlag, New York, 1991.

[19] L. Junwei, W.W. Tan, A type-2 PI controller with adjustable type-reduced output, in: Proceedings of NAFIPS, Montrèal, Canada, 2006, pp. 519-524.

[20] A. Kandel, Y. Luo, Y.-Q. Zhang, Stability analysis of fuzzy control systems, Fuzzy Sets Syst. 105 (1999) 33-48.

[21] N.N. Karnik, J.M. Mendel, Applications of type-2 fuzzy logic systems: handling the uncertainty associated with surveys, in: Proc. FUZZ-IEEE, Seoul, Korea,1999, vol.3, pp. 1546-1551.

[22] N.N. Karnik, J.M. Mendel, Operations on type-2 fuzzy sets, Fuzzy Sets Syst. 122 (2000) 327-348.

[23] N.N. Karnik, J.M. Mendel, Q. Liang, Type-2 fuzzy logic systems, IEEE Trans. Fuzzy Syst. 7 (1999) 643-658.

[24] N.N. Karnik, J.M. Mendel, Type-2 fuzzy logic systems: type-reduction, in: Proceedings IEEE Conference of Systems, Man and Cybernetics, San Diego, CA, 10, 1998, pp. 2046-2051.

[25] G. Kevrekidis, R. Aris, L.D. Schmidt, The stirred tank forced, Chem. Eng. Sci 41 (1986) 1549-1560.

[26] G.J. Klir, M.J. Wierman, Uncertainty-Based Information, Physica-Verlag, Heidelberg, Germany, 1998.

[27] C.D. Li, J.Q. Yi, Y. Yu, D.B. Zhao, Inverse control of cable-driven parallel mechanism using type-2 fuzzy neural network, Acta Autom. Sin. 36 (2010) 459464.

[28] T.C. Lin, Based on interval type-2 fuzzy-neural network direct adaptive sliding mode control for SISO nonlinear systems, Commun. Nonlinear Sci. Numer. Simul. 15 (2010) 4084-4099.

[29] T.C. Lin, M.C. Chen, M. Roopaei, Synchronization of uncertain chaotic systems based on adaptive type-2 fuzzy sliding mode control, Eng. Appl. Artif. Intell. 24 (2011) 39-49.

[30] T.C. Lin, H.L. Liu, M.J. Kuo, Direct adaptive interval type-2 fuzzy control of multivariable nonlinear systems, Eng. Appl. Artif. Intell. 22 (2009) $420-430$.

[31] C. Lynch, H. Hagras, V. Callaghan, Using uncertainty bounds in the design of an embedded real-time type-2 neuro-fuzzy speed controller for marine diesel engines, in: Proceedings of FUZZ-IEEE, Vancouver, Canada, 2006, pp. 7217-7224.

[32] R. Martínez, O. Castillo, L.T. Aguilar, Optimization of interval type-2 fuzzy logic controllers for a perturbed autonomous wheeled mobile robot using genetic algorithms, Inform. Sci. 179 (2009) 2158-2174.

[33] J.M. Mendel, Uncertainty, Type-2 fuzzy sets, and footprints of uncertainty, in: Proceeding of 9th International Conference on Information Processing and Management of Uncertainty in Knowledge Based Systems, Annecy, France, 2002, pp. 325-331.

[34] J.M. Mendel, Q. Liang, Pictorial comparisons of type-1 and type-2 fuzzy logic systems, Intell. Syst. Control (1999) 280-285.

[35] J.M. Mendel, Uncertain rule-based fuzzy logic systems, Introduction and New Directions, Prentice Hall, New Jersey, 2001. pp. 287-289.

[36] J.M. Mendel, <http://sipi.usc.edu/ mendel/software/>.

[37] C. Montana Lampo, V. Bartolozzi, A. Picciotto, M. Galluzzo, Adaptive Fuzzy Control of a Process with Bifurcation, Nonlinear Dynamics and Control, in: G. Continillo, S. Crescitelli, M. Giona (Eds.), Process Engineering - Recent Advances, Springer, Milan, 2002, pp. 209-225.

[38] M. Perez, P. Albertos, Self-oscillating and chaotic behaviour of a PI-controlled CSTR with control valve saturation, J. Process Control 14 (2004) 51-59.

[39] M. Perez, R. Font, M.A. Montava, Regular self-oscillating and chaotic dynamics of a continuous stirred tank reactor, Comput. Chem. Eng. 26 (2002) 889901.

[40] I. Robandi, B. Kharisma, Design of interval type-2 fuzzy logic based power system stabilizer, Int. J. Elect. Power Energy Syst. Eng. 2 (2) (2009) 73-80.

[41] L.P. Russo, B.W. Bequette, Effect of process design on the open-loop behaviour of a jacketed exothermic CSTR, Comput. Chem. Eng. 20 (1996) 417-426.

[42] R. Sepulveda, O. Castillo, P. Melin, A. Rodriguez-Diaz, O. Montiel, Experimental study of intelligent controllers under uncertainty using type-1 and type2 fuzzy logic, Inform. Sci. 177 (2007) 2023-2048.

[43] M. Sugeno, G.T. Kang, Structure identification of fuzzy model, Fuzzy Sets Syst. 28 (1998) 15-33.

[44] D. Wu, W.W. Tan, A type-2 fuzzy logic controller for the liquid-level process, in: Proceedings of IEEE International Conference on Fuzzy Systems, Budapest, Hungary, 2004, pp. 953-958.

[45] L.A. Zadeh, The concept of a linguistic variable and its applications to approximate reasoning-1, Inform. Sci. 8 (1975) 199-249.

[46] L.A. Zadeh, Fuzzy sets, Inform. Control 8 (1965) 338-353.

[47] L.A. Zadeh, Toward a generalized theory of uncertainty (GTU) - An outline, Inform. Sci. 172 (2005) 1-40. 